\title{
A LABORATORY TOOL FOR THE STUDY
}

OF VEHICLU VIBRATION PERFURIIANCE

\author{
S. A. ABOU-EL-SEOUD
}

ABSTRACT

The study of the vibration characteristics in machines has taken a front seat in engineering effort. This is particularly true in the automotive industry, where marketing a vibrating vehicle is unacceptable. Today's automobiles are a complex spring-mass-damper system which is excited into various modes of vibration. The vibrational modes falling in $10-200 \mathrm{~Hz}$ are. termed "structure shake", and produce distrubances seen and felt by the vehicle occupant. The knowledge of an objectionable vibration in developnent programs. Therefore, the aim of this work is to introduce a method by which -the vehicle vibration performance can be investigated in the laboratory. chassis dynamometer was used to simulate the road-going conditions. The measurement and analysis techniques are presented herein. Samples from the results obtained for van and small saloon vehicles are included to illust-: rate the suitability of the measuring technique and the instrumentation system used.

\section{INTRODUCTION}

As the vehicle is traversed over varying road surfaces and operated through a varying speed range, it is excited both externally and internally into various modes of vibration. One of the main objectives of automotive engin-eers over the years has been to design and develop vehicles in which the :passenger's perceptance of these vibrations, either through, sight, feel, or hearing is held to an absolute minimum under all driving conditions. une of the earliest techniques for accomplishing this, and one which still to some degree in use today, is the subjective, seat-of-the-pants evaluation by experienced personnel. Intuitive changes would be made in the vehicle and each one evaluted until satisfactory arrangement was arrived at [I]. :This method of solving structure problems leaves a lot to be desired as far as defining the problem and arriving at an efficient, economical solution in a minimum amount of time. The static bending test came into universal use. The technique considers the vehicle structure as a beam. The beam was supported on knife edges at the front and rear wheel centrelines, and either a constant bending moment was applied to each end or a torque was applied one end to produce beaming and torsional deflections. Vertical deflection

* Associate Professor, Dept. of Mechanical Engineering, Faculty of Lng. a Technology, EI-minia University, El-minia, Egypt. 
at various points on the structure was reasured and plotted to give static bending curves $[2,3]$. The results gave valid comparisons between cars and some indication of their stmuctural characteristics. Usually, a good deal

: of experience with the baseline model was required in order to predict the performance of the new model from the static bending curves. These results told very li.ttle about the vibration characteristics of the vehicle. The electrodynamic shaker came into use as another tool in studying structure vibration characteristics. It is in widespread use today and allows the engineers to make valid studies and analyses of the dynamics of an autom-

: otive structure. Through the use of multiple shaker systems, it is possible to excite in the laboratory the various modes of vibration of an automobile and study their tuning characteristics and the coupling between them. The

: inputs from the shakers can be fed directly in the structure at one or many points [4], or can be fed into the wheel spindles to more closely approximate road inputs $[5,6]$. Usually, the electrodynanic shaker study is

: concerned with exciting and separating pure modes so that various vibration analysis techniques can be applied to the system under study.

$\vdots$ As the knowledge of vehicle stmucture dynamics expanded during the past few years, it becomes more obvious that, in addition to pure inputs to the structure, a complete analysis must include inputs that simulate road

: inputs as closely as possible. Since road inputs consist basically of a vertical force or displacement acting at the contact patch of each tyre, this then becomes the logical place to introduce laboratory inputs. By

: doing this, it is then possible to duplicate in the laboratory the actual vibrations(or shake) experienced on the road, bringing all vehicle parts into play, and allowing complete instrumented and subjective analyses of

: the vehicle structure under controlled conditions, this is can be done by road simulator. However, the present paper does so by using a chassis dynamometer. The measuring system used is described and some typical

: results presented.

\section{THE NEED FOR TESTING}

The explanation of vibration generally begins with the theoretical development of formulas describing the vibration of arbitrarily chosen simple systems, such as the spring-mass system with one degree-of-freedom as : shown in Fig. 1.a. Equations are developed that describe the vibration characteristics of the system and then damping is usually added and the equations modified accordingly.

If another spring and mass is added as shown in Fig. 1.b, the system contains two degrees-of-freedom, and the equations describing its vibrations become more complex. As more springs, masses, viscous and coulomb damping : are added, the number of degrees-of -freedom increases as does the complexity of its characteristic equations. Although some of the automobile's mechanisms may be represented by a mathematical model. involving an awesome: array of formulas, the only practical way is to measure the actual and total vehicle response is through well planned testing. Various testing approaches used may be generally divided into three categories; namely, evaluation, ¿ diagnostic and development. The evaluation test is the basic form of a vibration appraisal. It may include making individual or jury subjective ratings : or quatitative measurement, or both, and frequently involves simple comparisons. However, the analysis in this work concerns with an laboratory : ${ }^{\text {eva }}$.. 

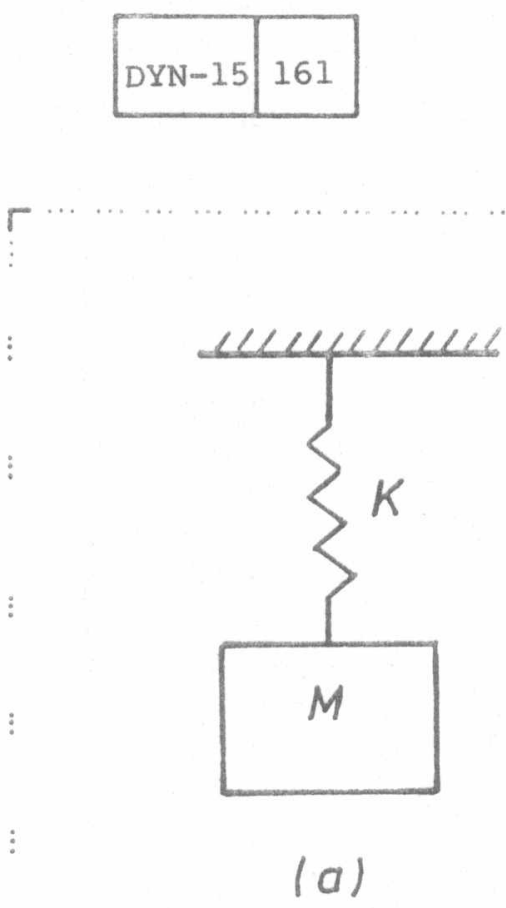

Fig. I Simple spring-mass system

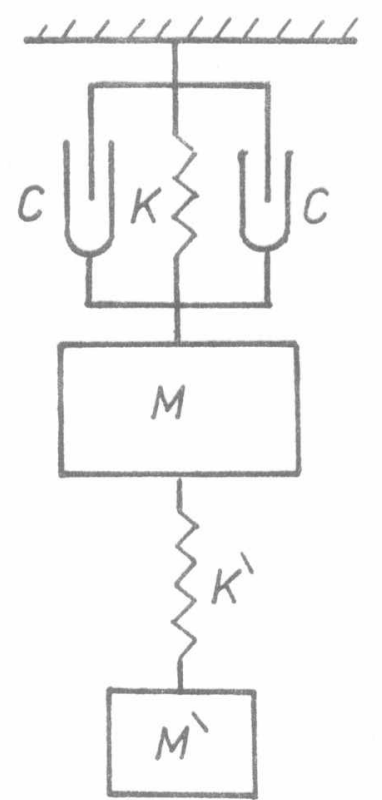

SIMULATION AND NEASURING SYSTEMS

The simulation procedure for the road conditions can be made by using a : :chassis dynamometer and is shown schematically in Fig. 2. This type of

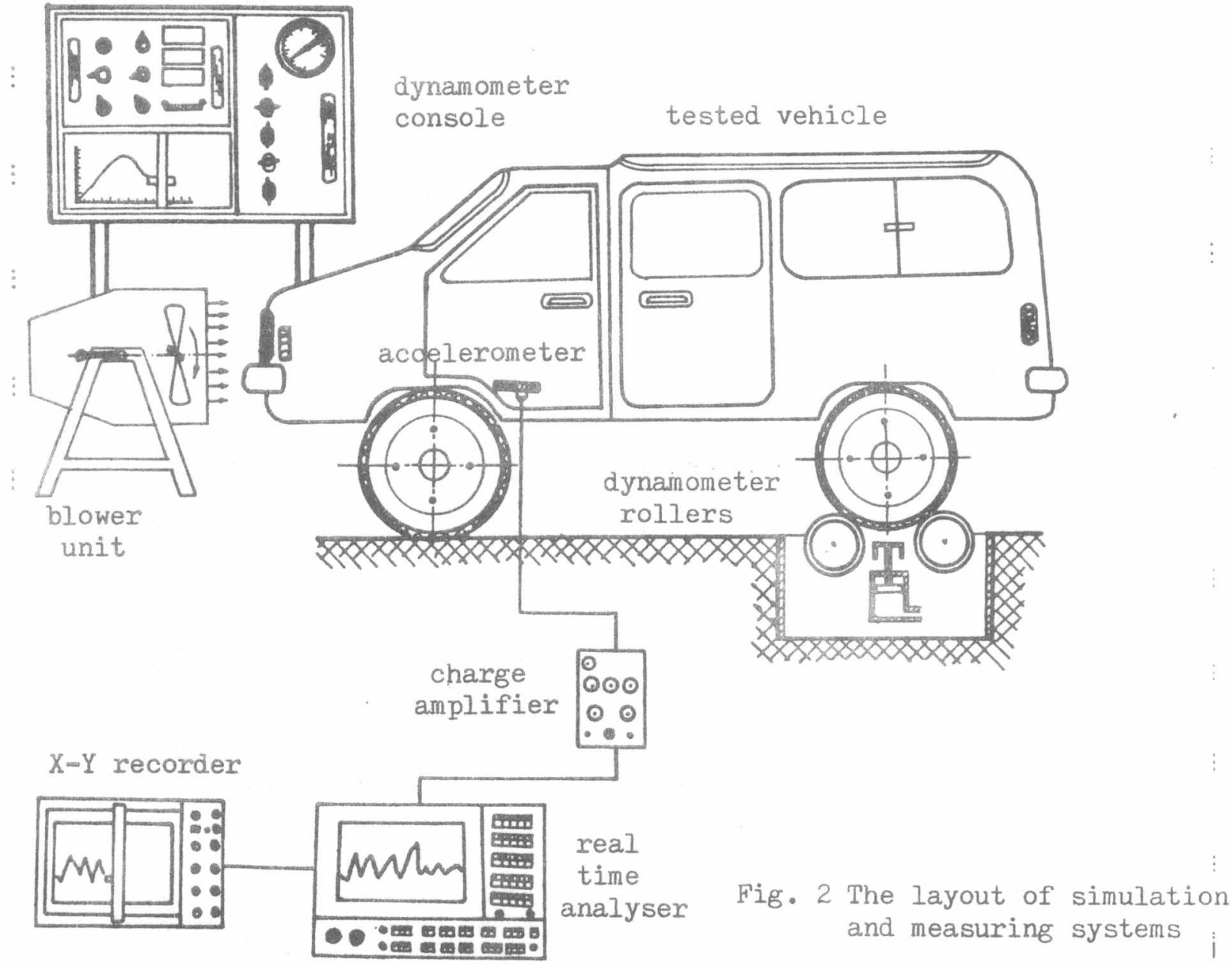


dynamometer is is. Mechanical Engineering Department, El-minia University. It gives the possibilty to simulate to a very large extent all actual road conditions, so that the adjustment and checking for the whole vehicle can : be done. It consists of two rollers of $2000 \mathrm{~mm}$. diameter and the circumference is exactly $1000 \mathrm{~mm}$., which support the rear vehicle wheels during test. The rollers are most carefully balanced, both dynamically and statically. They designed for quiet operation and have clase fitting protective covers to allow maximum safe access to all parts of the vehicle underside. In adition to absorbing or producing power at the vehicle rear wheels, the : eddy-current brake has the added capability of simulating varies road surface. Simulations of vehicle inertia, frontal wind(air) resistance, and crade loads are possible through electronics incorporated into the operator "s console. The brake is dimensioned to measure $150 \mathrm{KW}$ and $5000 \mathrm{~N}$. The allowable maximum speed is $180 \mathrm{kM} / \mathrm{hr}$. In order to prevent over-speeding the brake automatically increases the load at approximate this speed so that the speed camnot exceed $190 \mathrm{kM} / \mathrm{hr}$. The brake is water-cooled, and the water supply is controlled automatically with a built-in thermostatic sensing element. A high capacity blower unit is equipped for radiator cooling, engine, under-: body spot cooling, and a special localizer water system for tyre roller contact cooling. The control of the dynamometer is from a conplete operator's console, or from a remote control suitable for use outside or inside the vehicle. A unique feature of the vehicle dynamometer is its capability to The test vehicle may be operated over either of these surfaces and may be switched from one surface to the other.

The measuring system is also shown in Fig. 2. The system is partially Igital in operation. A uni-gain piezoelectric accelerometer is used. It generates an electrical output when subjected to mechanical shock or vibration. Over a wide dynamic range and frequency range its electrical output is directly proportional to the acceleration of the vibration applied at is base. The uni-gain type indicates that their charge sensitivity has been specially adjusted to within $2 \%$ of a convenient value. The electrical signal output from the accelerometer is intered to a charge amplifier. The amplifier is a comprehensively equipped and intended for general vibration measurements with a piezoelectrical accelerometer imput and for underwater cund measurements in conjunction with piezoelectric hydrophones. It can be wowed from internal batteries or an external DC power supply and is equally suitable for portable use in the field and for general laboratory 12se. The amplifier output is routed to the high resolution signal analyser. hich represents a significant innovation in the world of real time FFI analysis. The analyser has the capability of analysing the transient and nonstationary signals. Further a unique zoom feature which preserves the ime function allows a $4000-1$ ine spectrum to be generated from a single ime record. It consists of a combined transient recorder and fourier nalyser. The transient recorder has a $10 \mathrm{~K}$ sample memory, and is equipped vith an extremely flexible trigger allowing the analyser to analyze both continuous and transient signals. A graph plots for the analyser output both in frequency and amplitude can be taken through a X-Y recorder. It is outstanding dynamic performance and versatility, combined with its simple: and straight-forward operation. Its writing system can accept up to A4 paper size. The pen and the pen carriage are driven by low inertia servo motors Which are fully protected against excessive drive current and overloads.
For more description with other application. by using such measuring system can be found in [?] 


\section{APPLICAIIONS}

Vehicle Preparation and Test Procedure

"Two applications were made in this study. The first one was applied on Van vehicle which used for engine vibration tests, and the second one was applied on small saloon vehicle which used for road surface vibration tests. Some :specifications for these vehicles are listed in Table 1:

Table 1 Some vehicles specifications

\begin{tabular}{|c|c|c|c|}
\hline No. & parameter & Van & small Saloon \\
\hline $\begin{array}{l}1 \\
2 \\
3 \\
4 \\
5 \\
6 \\
7\end{array}$ & $\begin{array}{l}\text { tyre size } \\
\text { wheel base, m } \\
\text { wheel track, } \\
\text { height, } \\
\text { engine max. power,HP } \\
\text { gear-shift No. } \\
\text { gross vehicle weight } \\
\text { (GVW), Kg }\end{array}$ & $\begin{array}{l}180-13 \\
2.75 \\
1.47 \\
1.45 \\
95 \\
4 \& \text { rev. } \\
1200\end{array}$ & $\begin{array}{c}200-13 \\
3.69 \\
1.69 \\
2.22 \\
91 \\
4 \& \text { rev. } \\
1500\end{array}$ \\
\hline
\end{tabular}

Fig. 2 shows the van vehicle setting on the dynamometer along with the measuring instrumentations. Prior to testing, the tyres inflation pressure was measured and adjusted on 2.55 atm for each vehicle. It is recommended to increase the inflation pressure up to $50 \%$ for long run test. This will decrease tyre rolling resistance and consequently increase tractive force little. The cooling water and oil lubrication were checked, the hub caps and loose wheel weights were removed. The blower unit was switched on when the cooling water in the radiator has reached the normal working temperature of : each vehicle. The vehicle has been driven at moderate speed unil the engine has reached the normal working temperature. The tractive force preselector has been set to a value corresponding to the type of road surface condition. By this way, a constant and indefinitely reproducable load in the full speed range of the dynamometer irrespective of the durion of the test can be obtained. Consequently, the vehicle can be driven at any gear-shift and at any speed. It is well-known that the vibration generated from either road surface or engine is transmitted through their connection points with the body. Fig. 3 shows the layout of rear engine mount of Van vehicle considered. for engine vibration.

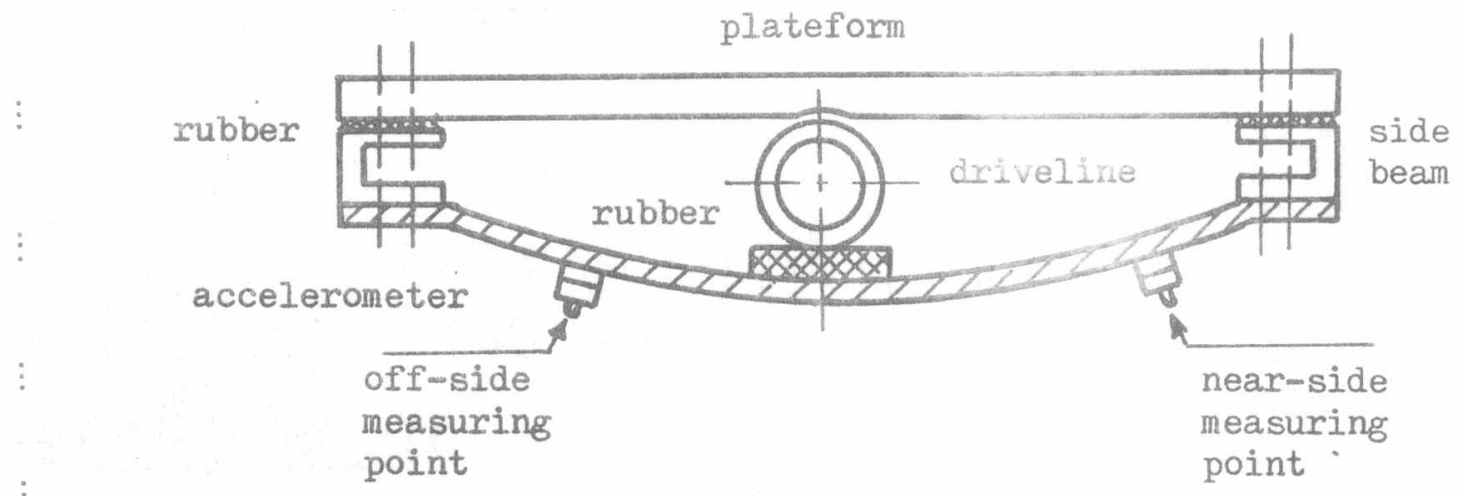

Fig. 3 The layout of rear engine mount of Van vehicle 
Once all the inicial provisions of measuring system such as adjustment, calibration and installation of vibration accelerometer, charge amplifier, analyser and $X-Y$ recorder have been made, a details measurements are begun

: by setting the vehicle speed as required and according to the chosen gearshift. The tractive force may be setting equal to zero or to any value corresponding to the type of road surface. The analyser can produce either instanteneous or average spectrum. Bearing in mind that the frequency range taken for engine vibration is $5 \mathrm{KHz}$ while in road surface vibration is $0.2 \mathrm{KHz}$. Table 2 lists the types of road surface used with their coeffic: ients of rolling resistance.

Table 2 The types of road surface and their coefficients of rolling resistance

\begin{tabular}{|c|c|c|}
\hline No. & $\begin{array}{l}\text { type of road } \\
\text { surface }\end{array}$ & $\begin{array}{l}\text { Coeff. of roll. resistance } \\
f \text {, mean value }\end{array}$ \\
\hline $\begin{array}{l}1 \\
2 \\
3\end{array}$ & $\begin{array}{l}\text { Cobblestone pavement } \\
\text { Gravel road } \\
\text { Asphalt-concrete }\end{array}$ & $\begin{array}{l}0.023-0.030 \\
0.020-0.025 \\
0.018-0.020\end{array}$ \\
\hline
\end{tabular}

Engine Vibration Results

:

Having applied the above procedure on the van vehicle in order to measure its engine vibration. Samples of the results obtained are shown in Figs. 4 , 5,6 and 7 . The frequency range used is $5 \mathrm{kHz}$ and the vibration response is presented as vibration acceleration referance to $1 \times 10^{-4} \mathrm{~m} / \mathrm{sec}^{2}$. The measu: ring points are being near-side and off-side of the rear engine mount. :

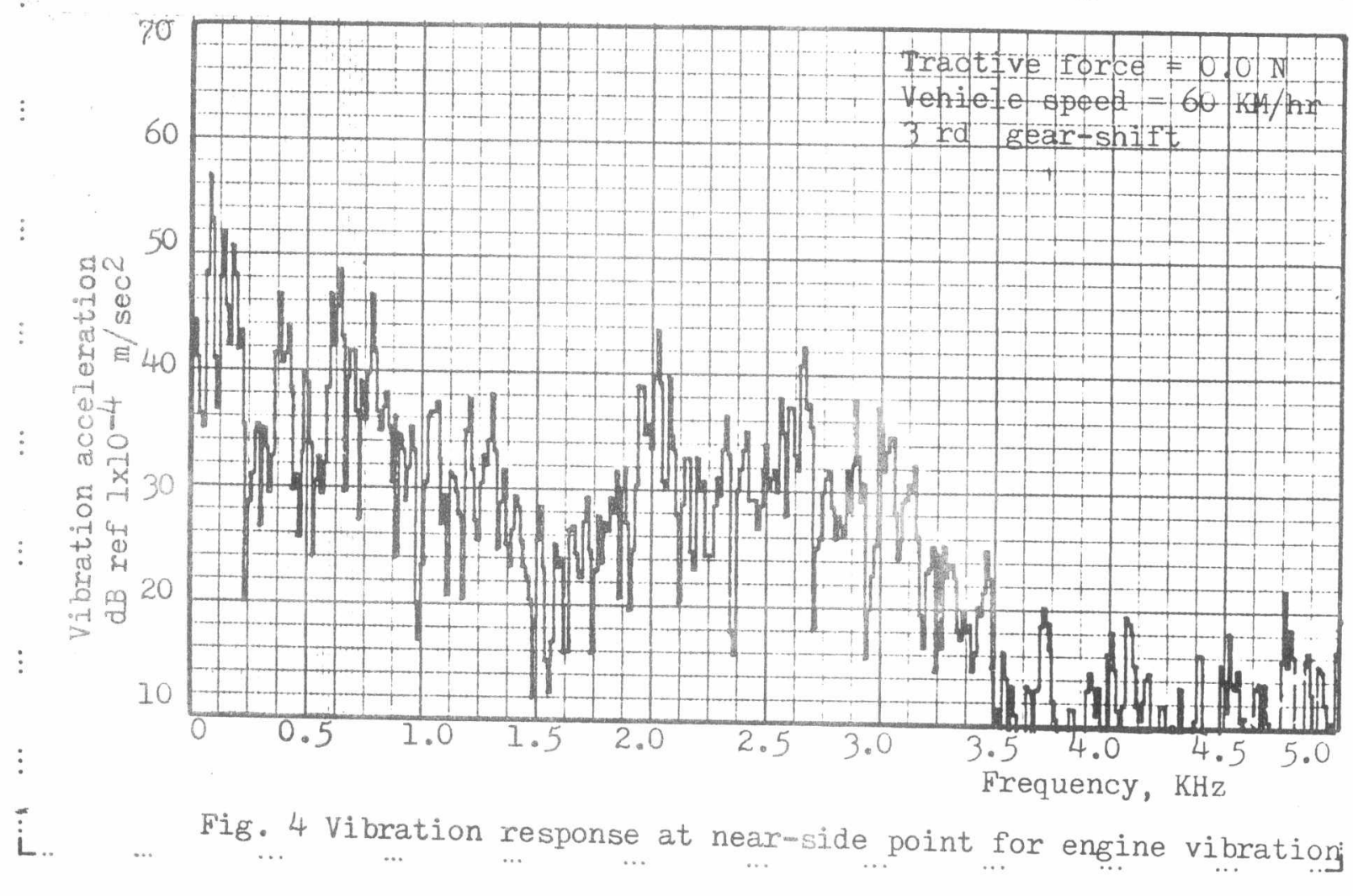




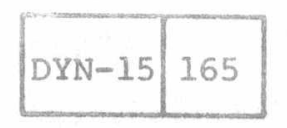

FIRST A.M.E. CONFERENCE

29-31 May 1984, Cairo

6

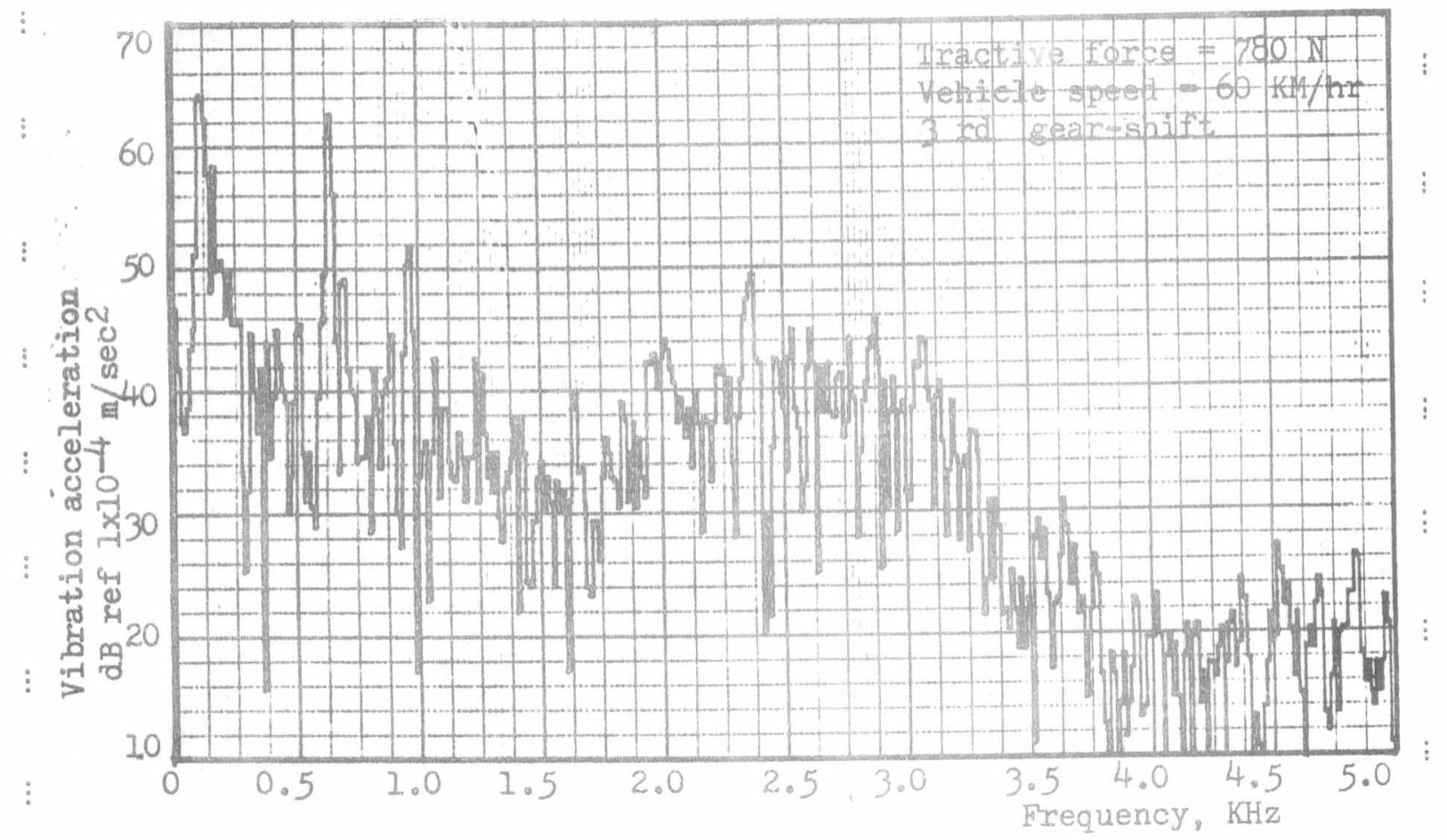

: Fig. 5 Vibration response at near-side point for engine vibration

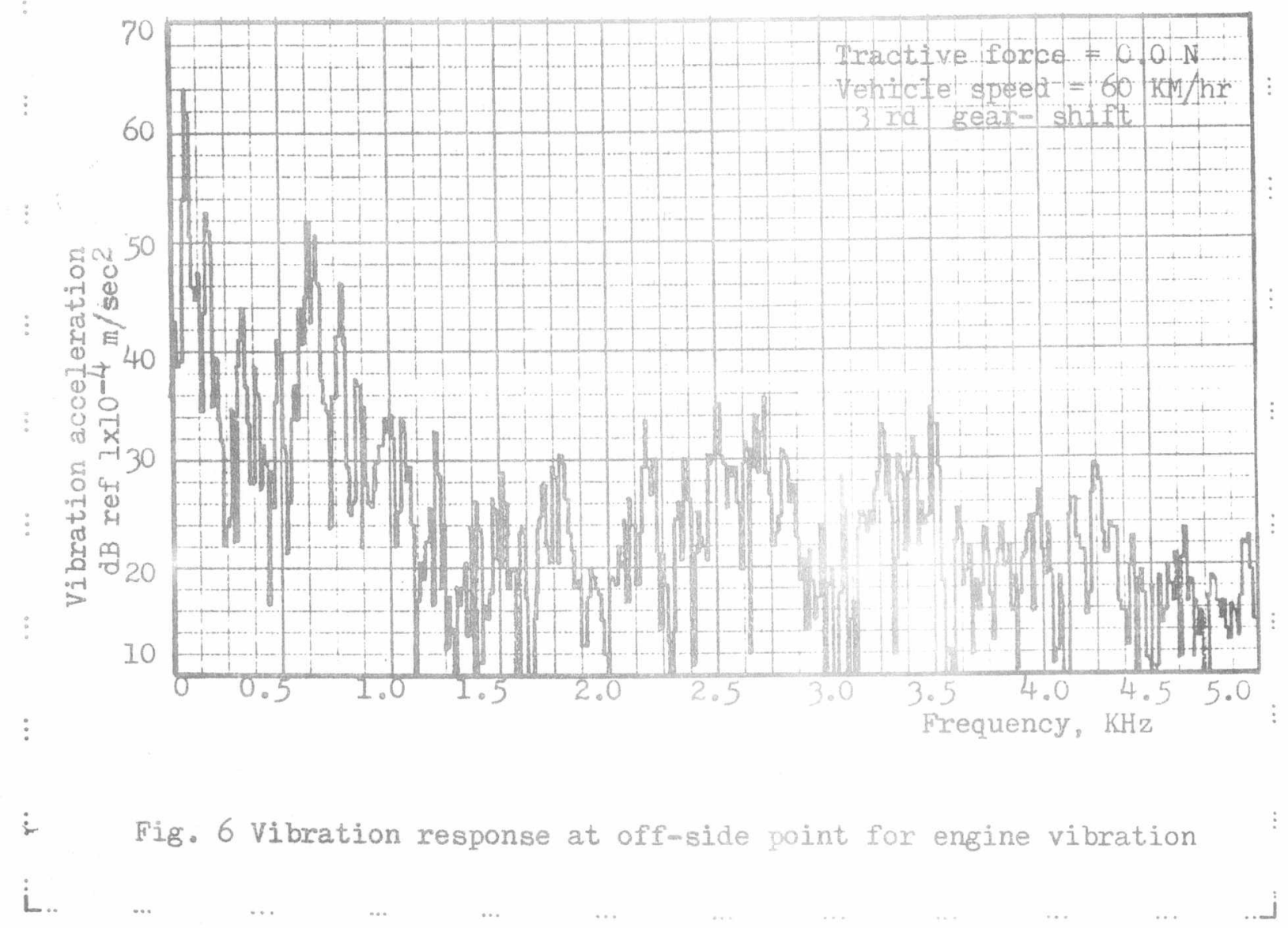


\begin{tabular}{|l|l|}
\hline DYN-15 166 \\
\hline
\end{tabular}

FIRST A.M.E. CONFERENCE

29-31 May 1984, Cairo

$\Gamma$

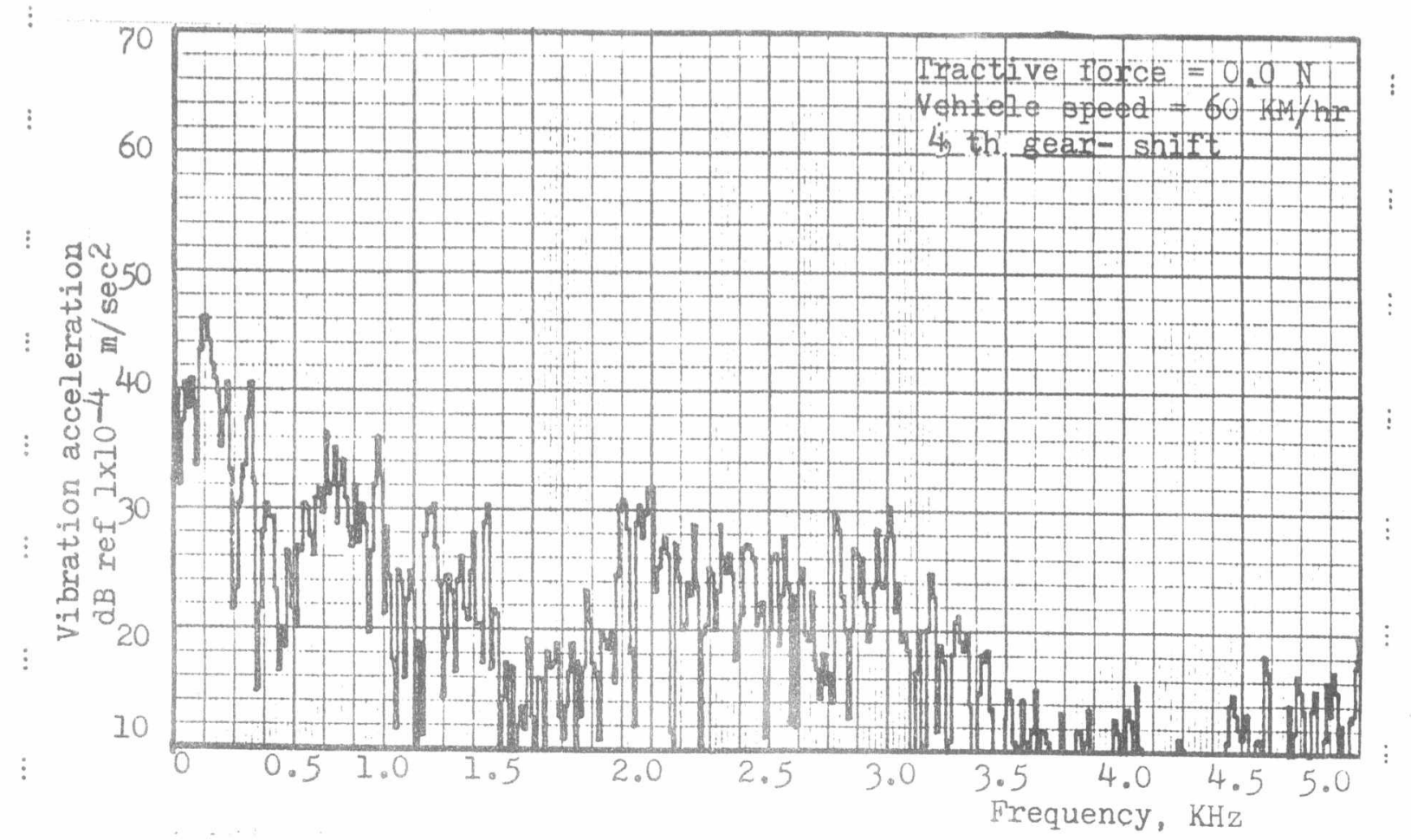

Fig. 7 Vibration response at near-side point for engine vibration

Figs. 4 and 5 show the vibration responses measured at near-side point when the vehicle run at $60 \mathrm{kM} / \mathrm{hr}$ on the $3 \mathrm{rd}$ gear-shift. The tractive force was zero (Fig.4) and equal to $780 \mathrm{~N}$ (Fig. 5). It is clearly seen from both figures that the same trend for the vibration responses is obtained, while the $1 \mathrm{KHz}$. This amplitudes arise in both cases in the frequency range up to combustion may be attribted to the excitation force generated from the at wheel/rol Fig. 4 with observed when comparing the results in obtained at off-sid Fig. 5, and it is very small. Fig. 6 shows the results lack of compari-side point for the same conditions as in Fig. 4 . For the be stated that vibration responses in the two points, it can when these results take be treated separately. can be found from the vibration behave comparison between Figs. 4 and 7, which indicates that is higher than that mear of near-side point of measurement at 3 rd gear-shift responses the same.

\section{Road Surface Vibration Results}

Having applied the above procedure on the small Saloon vehicle in order to: measure its road surface vibration. Samples from the results obtained are shown in Figs. 8,9,10 and 11. The frequency range used is $200 \mathrm{~Hz}$ and the vibration response is presented as vibration acceleration reference to $3.16 \times 10^{-4} \mathrm{~m} / \mathrm{sec}^{2}$. The measuring point was taken at off-side rear suspension. Figs. 8,9 and 10 show the acceleration responses measured at vehicle L. 
speed of $78 \mathrm{KM} / \mathrm{hr}$ on the $4 \mathrm{th}$ gear-shift. The tractive force values are :calculated from the vehicle dinemsions and coefficients of rolling resistance according to the type of road surface which present in Tables 1 and 2, then: the dynamometer was adjusted to give these values in order to simulate their :input. However, the tractive force of $560 \mathrm{~N}$ is corresponding to Gravel road (Fig. 8), $490 \mathrm{~N}$ is corresponding to Asphalt-concrete(Figs. 9 and 11 ) and $780 \mathrm{~N}$ is corresponding to Cobblestone pavement(Fig. 10). It can be in general

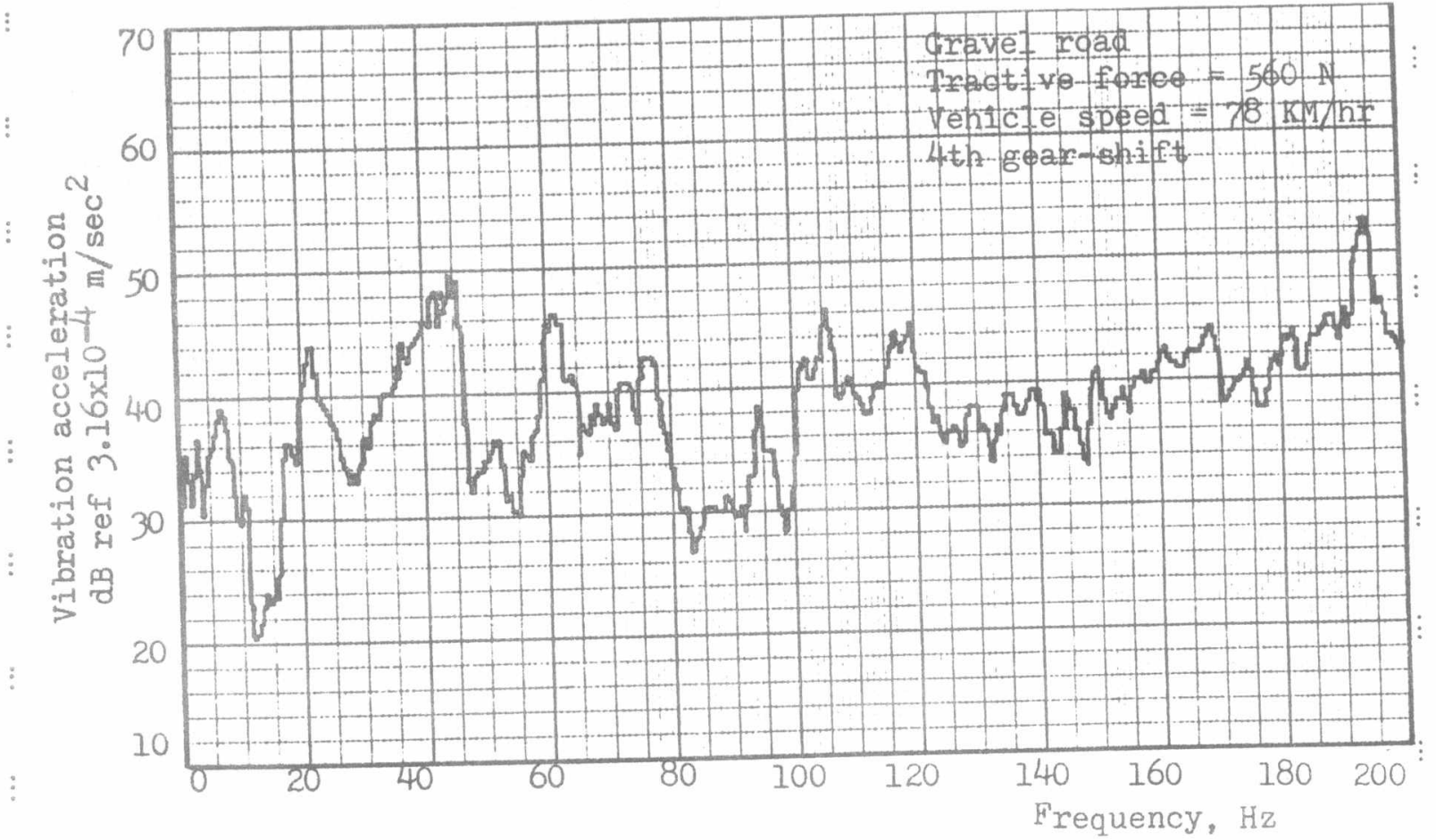

Fig. 8 Vibration response at off-side point for road surface vibration

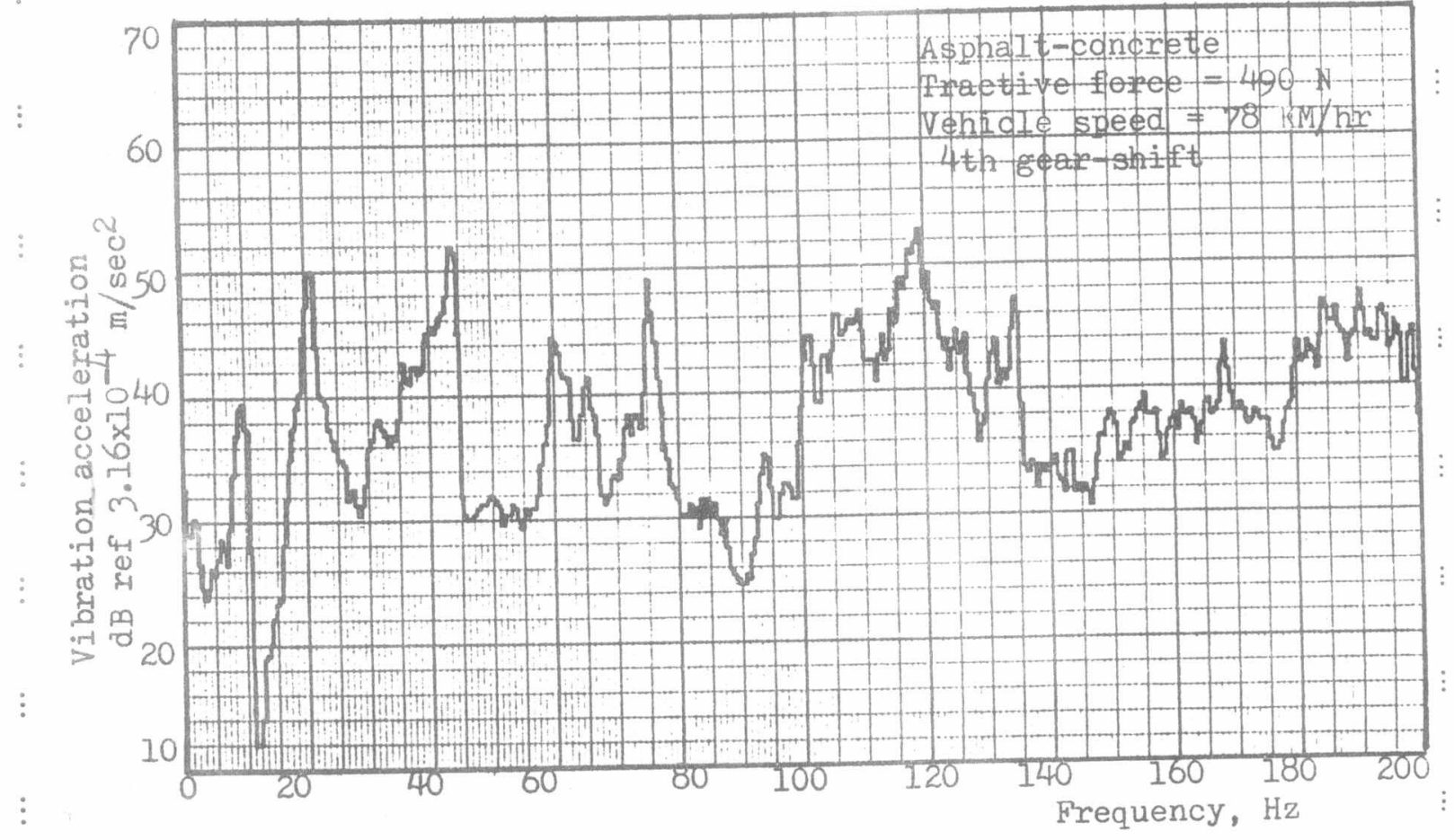

Fig. 9 Vibration response at off-side point for road surface vibration 


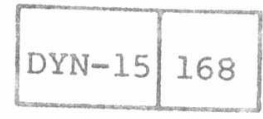

FIRST A.M.E. CONFERENCE

29-31 Nay 1984, Cairo

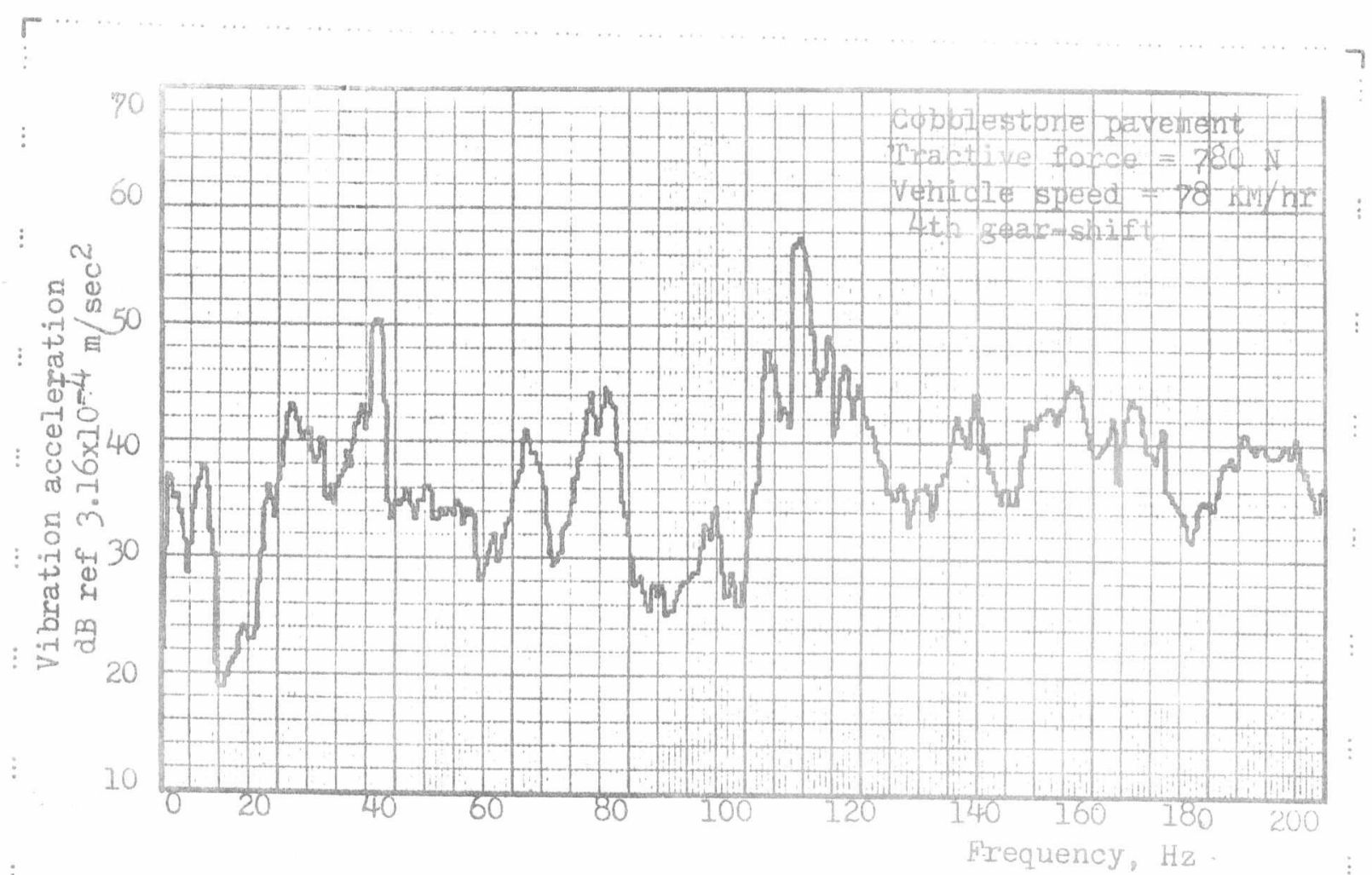

Fig. 10 Vibration response at off-side point for road surface vibration

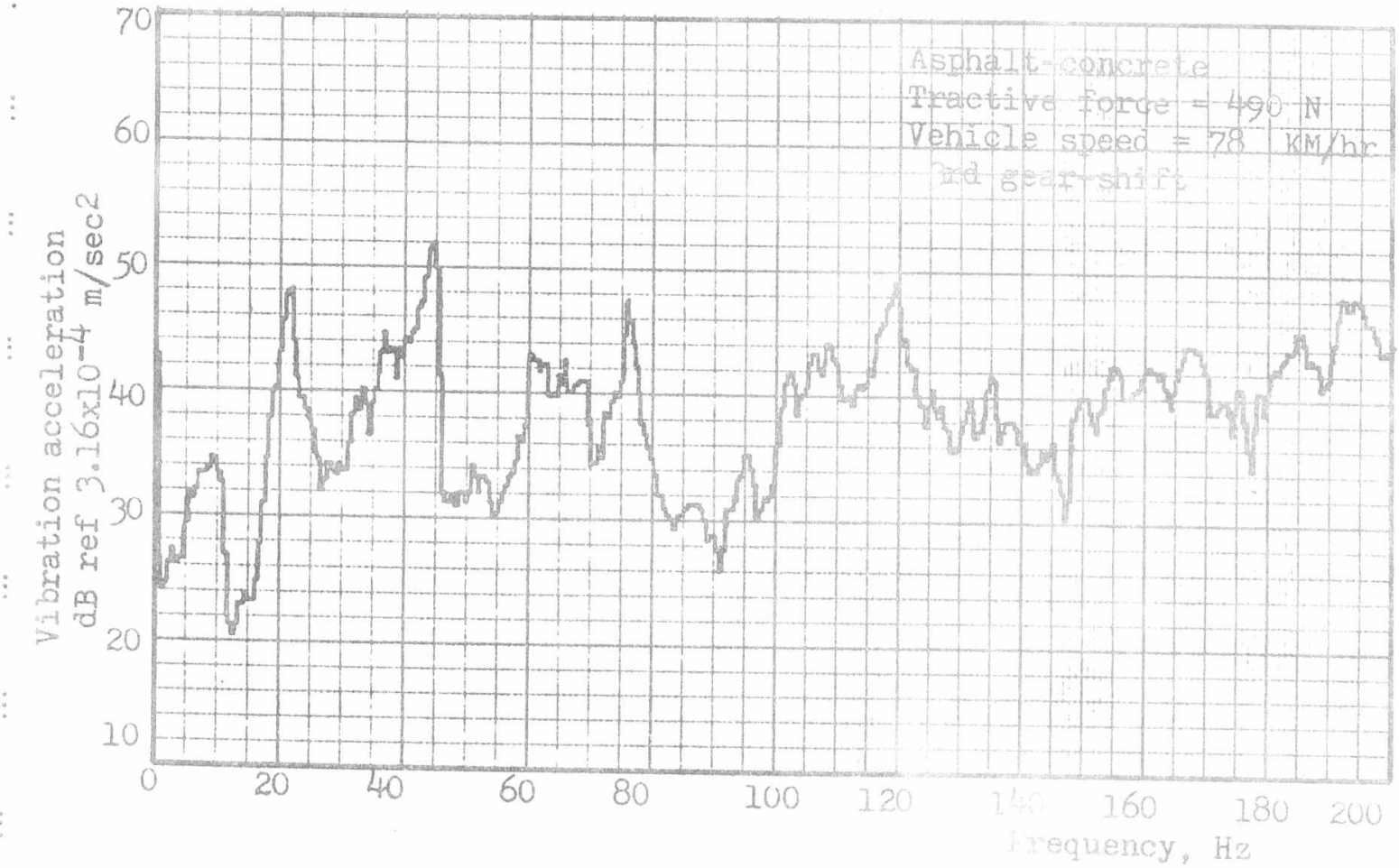

Fig. 11 Vibration response at off-side point fox

surface vibration

seen that the vibration responses measured at the same conditions are

changed fxom road surface to another, while the

: oxinately at the same frequencies

$\mathrm{Hz}$ and $175 \mathrm{~Hz}$. On the other hand the res $22 \mathrm{~Hz}, 45 \mathrm{~Hz}, 62 \mathrm{~Hz}, 75 \mathrm{~Hz}, 125$

L. (Fig. 9) are slightly higher than that measured for Gravel road surface 
particularly in frequency band of $100 \mathrm{~Hz}$ to $140 \mathrm{~Hz}$ (Fig. 8), while in the frequency band of $180 \mathrm{~Hz}$ to $200 \mathrm{~Hz}$ the responses at Gravel road are much higher. The same notice can be found in Fig. IU (pavement). In Fig. 11, the :vibration responses measured at the same vehicle speed of $78 \mathrm{kM} / \mathrm{hr}$ for the Asphalt-concrete surface only but at 3 rd gear-shift. The results in this figure when compared with that in Fig. 9 they indicate that the measured responses are higher at 3 rd gear-shift than that for the 4 th gear-shift. This may be attribeted to the fact that the engine vibration affects the response of road surface on 3rd gear-shift.

\section{$\vdots$}

\section{CONCLUSIONS}

1. The simulation and measuring systems used in assessing the vibration performance of vehicles are outlined.

2. The applications carxied out in this study give some insights about the : dynamic performance of the vehicles tested due to engine and road surface inputs. These tests need to be increased to cover all vehicle parts.

3. A related on-the-road analysis to provide experimental confirmation of the results involved in this study. This, in turn, will verify the control which various primary elements of the vehicle system have on the vibration performance generated.

4. A great information on the dynamic performance of vehicles could be obtained by using this technique. These information can be used to prov-:

: ide a means for predicting vibration response levels at the design stage by the finite element dynamic analysis.

1. Sogaian,A.M. Paliga,W.V., "Tools and Methods for Automotive Vehicle.

2. Noise and Vibration Testing" SAE Paper No. 670162 (1967). a Methematical Model for Automobile Beaming Shake" General Viotors Research Laboratory Report No. EM-41, Sept. ? (1965).

! 3. Sayer,J. and Mills,B."Static and Dynamic Analysis of a Iight Van Body Using the Finite Element Method" Paper P 15, Inst. of PhysicsAnnual Conference(Stress, Vibration and Noise Analysis in Vehicless, University of Aston, Birmingham, Sept.17-19 (1974).

4. Dunn,J.W., Ibrahim, A. and Mills,B." Rolling Tyre-Vehicle Dynarnic Analysis" Paper Presented at Inst. Meas. and Control Symposium.

! "Dynamic Analysis of Vehicle Ride and Manoeuvring Characteristics": London, 28-30 Nov. (1978).

5. Johnson,H.C.,"Application of Electrohydraulic Servo Control to

: Physical Testing" Proc. National Conference of Fluid Power, Vol. XVIII Oct. 22-23 (1964).

6. Spangler,E.B. and Kely,W.J. "GMR Road Profilometer" General Motors Research Laboratories Publication No. GMP-452, Dec. 22 (1964).

7. Abou-el-seoud, S.A., Abdel-aziz, F.F. and EI-sayed,F.M. "Measuring Techniques for the Analysis of Structural Vibration" 2nd Joint International Conference on Production Engineering, Leicester Polytecnic, England, 13th-15th April (1983). 
